\title{
Gated SPECT beyond myocardial perfusion: assessment of mechanical left ventricular synchrony
}

\author{
Erick Alexánderson-Rosas, ${ }^{\mathrm{a}}$ and Salvador Hernández-Sandoval ${ }^{\mathrm{a}}$ \\ a Nuclear Cardiology Department, Instituto Nacional de Cardiologia Ignacio Chávez, Mexico \\ City, Mexico
}

Received Dec 23, 2020; accepted Dec 24, 2020

doi: $10.1007 / \mathrm{s} 12350-020-02518-1$

\section{See related article, pp. 965-974}

Gated SPECT myocardial perfusion imaging (GSMPI) has a high sensitivity for the diagnosis and prognosis of coronary artery disease (CAD). We can evaluate not only myocardial perfusion but left ventricular function parameters (LVF). It has been established as the high prognostic value to predict major coronary events (MCEs) including cardiac death, mainly in poststress images. ${ }^{1,2}$

Otherwise, left ventricular systolic function, endsystolic and end-diastolic volumes, as well as the ejection fraction are strong cardiac death independent predictors despite myocardial perfusion. The role of myocardial perfusion and ventricular function has been extensively validated to predict MCEs. ${ }^{1-3}$

Usually, a normal MPI with normal LVF is associated with a low risk of coronary events, with a guarantee period that depends on the presence and control of coronary risk factors. ${ }^{4,5}$

Nevertheless, we can find balanced ischemia in subjects with multivessel disease, (false-negative study), despite the existence of an important coronary obstructive disease.

The coronary flow is generally decreased in the three coronary territories and remains relatively homogeneous with a problem to detect ischemia. ${ }^{6-9}$

Reprint requests: Erick Alexánderson-Rosas, Nuclear Cardiology Department, Instituto Nacional de Cardiologia Ignacio Chávez, Mexico City, Mexico; alexandersonerick@gmail.com J Nucl Cardiol 2022;29:975-7.

$1071-3581 / \$ 34.00$

Copyright (c) 2021 American Society of Nuclear Cardiology.
Nowadays, GS-MPI allows us to analyze left ventricular systolic function parameters, but it is also to analyze left ventricular mechanical dyssynchrony (LVMD) too (Fig. 1) ${ }^{10}$ The greatest utility has been found to select candidates with heart failure for cardiac resynchronization therapy (CRT), to decrease the percentage of non-responders, which is high around $20 \%$ to $40 \%$ (Fig. 2). ${ }^{11}$

The evaluation of LVMD is very simple, the study is acquired regularly in a conventional gamma camera, using the same injection and acquisition of the GS-MPI, but it requires special software for dyssynchrony analysis.

Phase standard deviation and phase bandwidth are the 2 most validated mechanical dyssynchrony parameters indicating the time it takes contraction of the ventricle within the cardiac cycle. ${ }^{12,13}$ Reference values of synchrony parameters in healthy subjects have been published and also the values to predict a high probability of response to CRT. ${ }^{10,14-16}$ But it is also necessary to demonstrate that the asynchronous area does not correspond to a necrotic zone, which can be easily done by comparing the synchrony image with the myocardial perfusion image. ${ }^{17}$

Another less used utility of the GS-MPI is the relationship of the infarction extent, the amount of ischemia burden, or left ventricle systolic dysfunction with the alterations in ventricular synchrony induced by physical or pharmacological stress and their prognostic value.

In particular, interesting is the hypothesis that in multivessel disease and balanced ischemia patients, a stress test can lead to a global left ventricular mechanical dyssynchrony (LVMD) observed with an increase of the dyssynchrony parameters from the baseline rest results. This utility could be a great advantage in multivessel disease and balanced ischemia patients. ${ }^{18,19}$ However, this alteration could also occur as a 


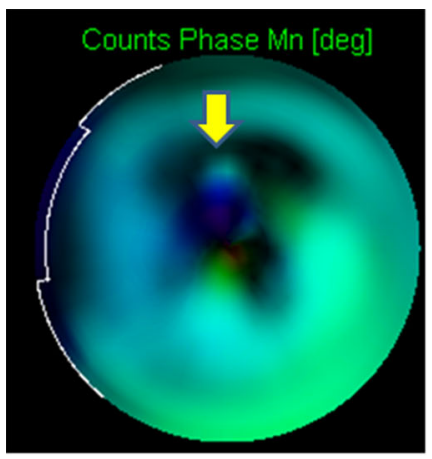

Polar map. Mechanical dyssynchrony location

\section{Mechanical dyssynchrony quantitation}

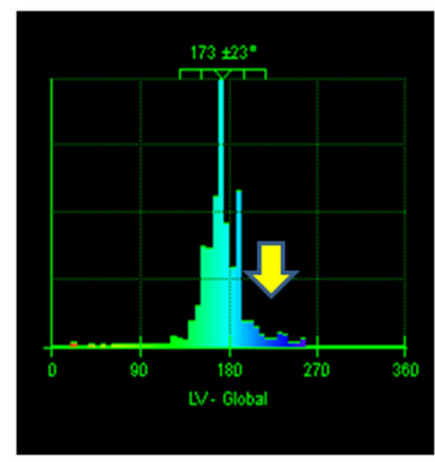

Standar deviation $\pm 23^{\circ}$ Bandwith $131^{\circ}$

\section{Relationship of the asynchronous area with the myocardial infarction}

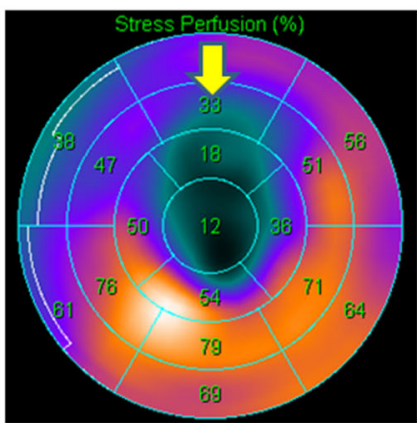

Figure 1. GS-MPI with LVMD in an area of perfusion defect caused by a myocardial infarction.
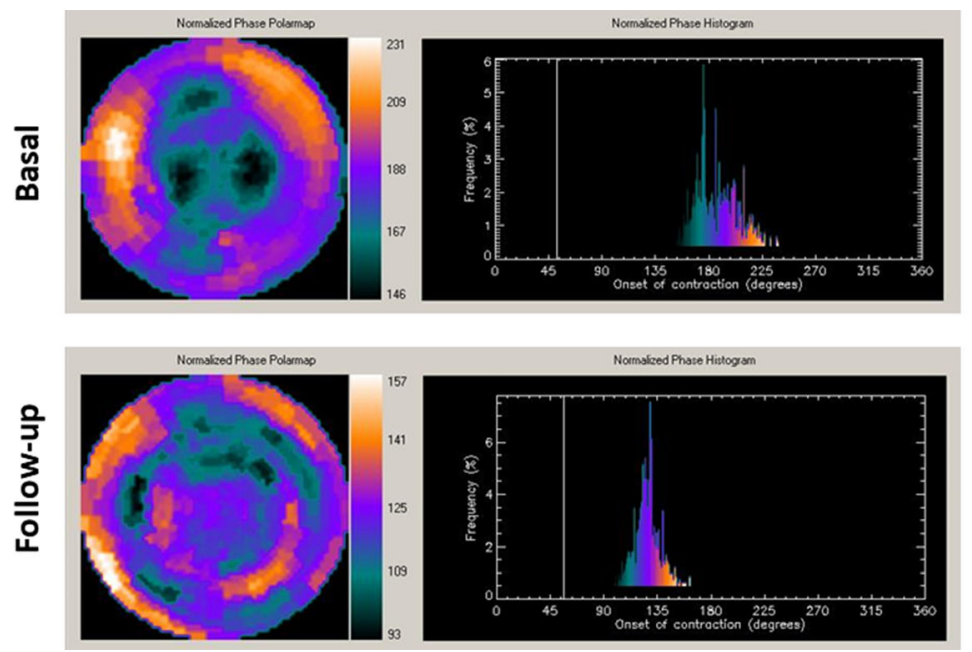

\begin{tabular}{lcc}
\hline & Basal & $\begin{array}{c}\text { Follow- } \\
\text { up }\end{array}$ \\
\hline LVEF \% & 40 & 50 \\
LVEDV ml & 101 & 88 \\
\hline LVESV ml & 35 & 20 \\
\hline LV Mass gr & 135 & 124 \\
\hline Histogram Standard Deviation 은 & 17 & 10.2 \\
\hline Last Viable Contracting Segment 을 & 225 & 160 \\
\hline
\end{tabular}

Figure 2. GS-MPI with LVMD assessment prior and 1-year follow-up CRT St Jude Allure Quadra implantation in DDDR mode.

consequence of baseline alterations in the left ventricular function that are accentuated by the stress test, even in the absence of ischemia, which would be more likely to occur with physical exertion and not with the use of coronary vasodilators. In any case, stress-induced left ventricular dyssynchrony could theoretically indicate a significant risk of major coronary events, deterioration in left ventricular function, or cardiac death.

Tomohiko Sakatani et al investigated retrospectively LVMD and evaluated the indices of phase bandwidth and phase standard deviation with ${ }^{99}$ TcTetrofosmine GS-MPI in subjects with normal 
myocardial perfusion imaging results. They separated patients who underwent physical $(\mathrm{N}=310)$ vs pharmacological stress $(\mathrm{N}=608)$ during the follow-up period of 2.2 years $( \pm 1.9$ years). They found that LVMD stress bandwidth induced by physical exercise stress was an independent predictor of MCEs in patients with normal perfusion SPECT (HR 1.017, CI 1.003-1.032, $P=$ $0.019)$, whereas pharmacological stress had no association with further events. ${ }^{20}$

Beyond the myocardial perfusion, GS-MPI provides important information in the analysis of mechanical left ventricular synchrony, which has proven to be useful in the selection of patients for cardiac resynchronization therapy, identifying perfusion artifacts and potentially balanced ischemia patients. Therefore, routine inclusion of this analysis should be considered and informed.

\section{Disclosure}

Erick Alexánderson-Rosas and Salvador Hernández-Sandoval have no conflicts of interest to disclose.

\section{References}

1. Hachamovitch R, Hayes SW, Friedman JD, Cohen I, Berman DS. Comparison of the short-term survival benefit associated with revascularization compared with medical therapy in patients with no prior coronary artery disease undergoing stress myocardial perfusion single photon emission computed tomography. Circulation. 2003;107(23):2900-7.

2. Hachamovitch R, Berman DS, Shaw LJ, Kiat H, Cohen I, Cabico JA, et al. Incremental prognostic value of myocardial perfusion single photon emission computed tomography for the prediction of cardiac death. Circulation. 1998;97(6):535-43.

3. Sharir T, Germano G, Kavanagh PB, Lai S, Cohen I, Lewin HC, et al. Incremental prognostic value of post-stress left ventricular ejection fraction and volume by gated myocardial perfusion single photon emission computed tomography. Circulation. 1999;100(10):1035-42.

4. Hachamovitch R, Hayes S, Friedman JD, Cohen I, Shaw LJ, Germano G, et al. Determinants of risk and its temporal variation in patients with normal stress myocardial perfusion scans. J Am Coll Cardiol. 2003;41(8):1329-40.

5. Small GR, Ruddy TD. Are there any guarantees with the warranty period for normal stress SPECT myocardial perfusion imaging? J Nucl Cardiol. 2020;27(2):542-6.

6. Williams K. Correct spatial normalization of myocardial perfusion SPECT improves detection of multivessel coronary artery disease. J Nucl Cardiol. 2003;10(4):353-60.

7. Nakanishi R, Gransar H, Slomka P, Arsanjani R, Shalev A, Otaki $\mathrm{Y}$, et al. Predictors of high-risk coronary artery disease in subjects with normal SPECT myocardial perfusion imaging. J Nucl Cardiol. 2016;23(3):530-41.
8. Abbott B. Prognostic significance of ischemic electrocardiographic changes during adenosine infusion in patients with normal myocardial perfusion imaging. J Nucl Cardiol. 2003;10(1):9-16.

9. Klodas E. Prognostic significance of ischemic electrocardiographic changes during vasodilator stress testing in patients with normal SPECT images. J Nucl Cardiol. 2003;10(1):4-8.

10. Chen J, Garcia EV, Folks RD, Cooke CD, Faber TL, Tauxe EL, et al. Onset of left ventricular mechanical contraction as determined by phase analysis of ECG-gated myocardial perfusion SPECT imaging: Development of a diagnostic tool for assessment of cardiac mechanical dyssynchrony. J Nucl Cardiol. 2005;12(6):687-95.

11. Miller EO, Malhotra S, Schwartz RG. Quantitative radionuclide assessment of cardiac dyssynchrony: Breakthrough in patient selection for cardiac resynchronization therapy for refractory heart failure? J Nucl Med. 2016;57(12):1840-2.

12. Chen J, Henneman MM, Trimble MA, Bax JJ, Borges-Neto S, Iskandrian $\mathrm{AE}$, et al. Assessment of left ventricular mechanical dyssynchrony by phase analysis of ECG-gated SPECT myocardial perfusion imaging. J Nucl Cardiol. 2008;15(1):127-36.

13. Chen J, Garcia EV, Bax JJ, Iskandrian AE, Borges-Neto S, Soman P. SPECT myocardial perfusion imaging for the assessment of left ventricular mechanical dyssynchrony. J Nucl Cardiol. 2011;18(4):685-94.

14. Hämäläinen H, Hedman M, Laitinen T, Hedman A, Kivelä A, Laitinen $T$. Reference values for left ventricular systolic synchrony according to phase analysis of ECG-gated myocardial perfusion SPECT. Clin Physiol Funct Imaging. 2018;38(1):38-45.

15. Henneman MM, Chen J, Dibbets-Schneider P, Stokkel MP, Bleeker GB, Ypenburg C, et al. Can LV dyssynchrony as assessed with phase analysis on gated myocardial perfusion SPECT predict response to CRT? J Nucl Med. 2007;48(7):1104-11.

16. Boogers MM, Van Kriekinge SD, Henneman MM, Ypenburg C, Van Bommel RJ, Boersma E, et al. Quantitative gated SPECTderived phase analysis on gated myocardial perfusion SPECT detects left ventricular dyssynchrony and predicts response to cardiac resynchronization therapy. J Nucl Med. 2009;50(5):71825.

17. Ypenburg C, Schalij MJ, Bleeker GB, Steendijk P, Boersma E, Dibbets-Schneider $\mathrm{P}$, et al. Impact of viability and scar tissue on response to cardiac resynchronization therapy in ischaemic heart failure patients. Eur Heart J. 2006;28(1):33-41.

18. Tanaka H, Chikamori T, Hida S, Igarashi Y, Shiba C, Usui Y, et al. diagnostic value of vasodilator-induced left ventricular dyssynchrony as assessed by phase analysis to detect multivessel coronary artery disease. Ann Nucl Cardiol. 2015;1(1):6-17.

19. Hida S, Chikamori T, Tanaka H, Igarashi Y, Shiba C, Usui Y, et al. Diagnostic value of left ventricular dyssynchrony after exercise and at rest in the detection of multivessel coronary artery disease on single-photon emission computed tomography. Circ J. 2012;76(8):1942-52.

20. Sakatani T, Kasahara T, Irie D, et al. Prognostic value of left ventricular mechanical dyssynchrony induced by exercise stress in patients with normal myocardial perfusion single-photon emission computed tomography. J Nucl Cardiol. 2020. https://doi.org/10. 1007/s12350-020-02389-6.

Publisher's Note Springer Nature remains neutral with regard to jurisdictional claims in published maps and institutional affiliations. 